\title{
SURVEY PENGETAHUAN GURU PJOK TENTANG PENANGANAN CEDERA OLAHRAGA DENGAN METODE RICE
}

\author{
Rio Rizqul Ramadhan ${ }^{1}$, Citra Resita ${ }^{2}$, Aria Yuda Kusuma R ${ }^{3}$. \\ Universitas Singaperbangsa Karawang ${ }^{1,2,3}$ \\ riorizqul123@gmail.com², citra.resita@fkip.ac.id ${ }^{2}$, ariayuda@rocketmail.com³
}

\begin{abstract}
ABSTRAK
Penelitian ini dilatar belakangi oleh guru pjok yang sangat berperan penting dan bertanggung jawab di lapangan saat pembelajaran olahraga. Penelitian ini bertujuan untuk mengetahui seberapa besar pengetahuan guru pjok tentang penanganan cedera olahraga dengan metode rest ice compression elevation (rice) di SMA \& SMK seKecamatan Telukjambe Timur. Penelitian ini merupakan penelitian deskriptif kuantitatif, metode yang digunakan adalah survey. Teknik pengumpulan data berupa angket menggunakan tes soal pilihan ganda. Populasi yang digunakan adalah guru pjok di SMA \& SMK se-Kecamatan Telukjambe Timuryang berjumlah 16 orang. Sampel yang digunakan dalam penelitian ini sebanyak 16 guru pjok dengan teknik pengambilan sampel yaitu total sampling. Hasil penelitian menunjukan guru pjok tentang penanganan cedera olahraga dengan metode rest ice compression elevation (rice) di SMA \& SMK se-Kecamatan Telukjambe Timur secara keseluruhan berada di kategori "tidak baik" dengan jumlah guru pjok 8 guru pjok dan presentase sebesar (50\%)
\end{abstract}

Kata Kunci: Pengetahuan; Pendidikan Jasmani; Metode RICE

\begin{abstract}
This research is motivated by the corner teacher who is very important and responsible in the field when learning sports. This study aims to find out whatever the corner teachers know about the injury with the elevation method of ice compression (RICE) in SMA \& SMK in East Telukjambe District. This research is a descriptive quantitative research, the method used is a survey. The data test technique was in the form of a questionnaire using multiple choice test questions. The population used is the corner teachers in SMA \& SMK in the Telukjambe District of Timuryang assigning 16 people. The sample used in the study was 16 teachers corner with the sampling technique that is total sampling. The results showed the corner teachers about sports injuries with the elevation method of resting ice compression (RICE) in SMA \& SMK in East Telukjambe District were overall in the "bad" category with 8 corner teachers and a percentage of (50\%)
\end{abstract}

Keywords: Knowledge; Physical Education; RICE Method

Dipublikasikan Oleh :

UPT Publikasi dan Pengelolaan Jurnal

Universitas Islam Kalimantan Muhammad Arsyad Al-Banjari Banjarmasin 


\section{PENDAHULUAN}

Pendidikan jasmani merupakan bagian integral dari pendidikan secara keseluruhan, bertujuan untuk mengembangkan aspek kebugaran jasmani, keterampilan gerak, keterampilan sosial, tindakan moral, aspek pola hidup sehat dan pengenalan lingkungan bersih melalui aktivitas jasmani, yang direncanakan secara sistematis dalam rangka mencapai tujuan pendidikan nasional

Kegiatan pembelajaran pendidikan jasmani agar berlangsung secara efektif dan strategi pembelajaran yang digunakan adalah dapat ditunjang oleh pemanfaatan media pembelajaran yang telah ditentukan (Fauzi 2020:38). Guru dituntut mampu menerapkan pembelajaran yang efektif yang sesuai dengan kebutuhan siswa dan setiap materi pembelajaran. Selain itu, guru harus mampu memodifikasi fasilitas serta media apabila kurang memadai dan kurang mendukung dalam melakukan pembelajaran pendidikan jasmani(Jamaliah, 2019:2). Pengetahuan tentang cara-cara pencegahan dan perawatan cedera bagi guru penjaskes sangatlah penting dimiliki karena pada dasarnya cedera yang dialami oleh siswa pada saat pembelajaran penjaskes berlangsung akan segera dapat ditangani oleh guru penjaskes tanpa harus langsung menuju rumah sakit ataupun pihak asli dalam penyembuhan cedera. Pencegahan dan perwatan pertama yang dilakukan oleh guru dapat meredakan cedera yang dialami oleh siswa, penanganan yang salah saat pertama kali dapat berakibat buruk dikemudian hari (Sihaloho, 2019:3).

Ada beberapa faktor yang menyebabkan cedera yaitu faktor internal, eksternal dan overused. Faktor internal adalah faktor penyebab cedera yang berasal dari dalam diri sendiri. Salah satu penyebabnya adalah siswa yang kurang melakukan pemanasan, saat melakukan gerakan, tubuh dapat terkena cedera karena fleksibilitas yang kurang terlatih. Faktor eksternal adalah faktor penyebab cedera yang muncul karena faktor dari luar, seperti karena lingkungan ataupun sarana dan prasarana. Contohnya lapangan yang tidak rata ataupun kurang memadai dan tidak aman. Terakhir adalah faktor overused. Faktor ini merupakan cedera yang disebabkan karena siswa melakukan aktivitas jasmani secara terus-menerus tanpa melalui fase istirahat. Usaha yang dilakukan untuk menangani cedera dini, menggunakan prinsip P3K dengan metode Rest Ice Compression Elevation. RICE dapat membantu penyembuhan cedera diantaranya: menghentikan dan mengurangi pendarahan dan pembengkakan pada pembuluh-pembuluh darah yang mengalami cedera, mengurangi dan menghilangkan rasa nyeri pada cedera yang disebabkan oleh pengaruh es. Selain dapat membantu dalam proses penyembuhan cedera olahraga, tindakan menangani cedera dengan menggunakan tindakan RICE merupakan tindakan penanganan yang mudah dilakukan oleh guru PJOK (Normaisyah et al., 2020:3).

Hasil observasi di lapangan pada bulan September sampai dengan bulan November tahun 2019 pada saat PLP, setiap hari Senin sampai dengan Jumat jam 00:07-10:00 WIB, pada saat pembelajaran Pendidikan jasmani tepatnya melakukan kegiatan pembelajaran Sepak Bola di Lapangan terjadi benturan Antara pemain yang menyebabkan siswa kedua-keduanya mengalami cedera di bagian engkel dan pergelangan tangan namun hal yang permata dilakukan oleh guru di sekolah tersebut yaitu memberikan balsam di area cedera tersebut alhasil pembengkakan menjadi lebih besar dan sembuh pun menjadi lebih lama dan saar jam istirahat banyak siswa yang berlarian dan melakukan aktivitas sembarangan yang dapat menyebabkan anak itu terjatuh sampai mengalami cedera dan mengakibatkan memar, seharusnya guru sebaiknya memberikan pertolongan pertama dengan memberikan sesuatau yang dingin seperti es, itu bertujuan mengurangi rasa nyeri dan memar agar bisa teratasi, akan tetapi dilapangan beberapa guru ada yang masih memberikan balsam atau minyak penghangat. Pemberian balsam ataupun minyak penghangat itu menyebabkan cedera yang dialami siswa tersebut menjadi semakin parah.

Menurut (Wijaya 2019:493). Cedera yang terjadi pada saat berolahraga harus mendapatkan perhatian yang lebih. Hal ini bertujuan untuk memberikan penanganan yang tepat dan sesuai cedera yang dialami. (Arsani, 2019) menjelaskan tentang hal yang perlu untuk diperhatikan dalam penanganan cedera, yaitu dalam 24-48 jam pertama setelah terjadinya cedera tidak boleh melakukan massage atau memanaskan bagian yang cedera karena dapat memperberat cedera, sehingga pengobatan yang dilakukan hanya menggunakan metode rest ice compression elevation. Penanganan menggunakan prinsip rest ice compression elevation dapat memberikan penanganan dini yang cepat, tepat dan aman terhadap reaksi peradangan pada cedera. Cara yang dilakukan yaitu dengan mengistirahatkan, memberikan es, penerapan balut tekan ringan, dan meninggikan posisi cedera. Keterangan lebih lanjut mengenai rest ice compression elevation.

Hal ini diperkuat oleh penelitian terdahulu (Arsani, 2019)dengan judul "Presepsi Guru Pendidikan jasmnai sekolah dasar se - kecamatan sewon dalam penanganan dini cedera olahraga dengan Rest Ice Compression dan Elevation". Hasil penelitian menunjukan bahwa prepsi guru pendidikan jasmani sekolah dasar se - kecamatan sewon dalam penaganan dini cedera olahraga dengan RICE ( Resr Ice Compression dan Elevation) adalah sedang secara rinci sebanyak 3 orang $(10,00 \%)$ dalam kategori baik sekali, 4 orang $(13,33 \%)$ dalam kategori baik, 15 orang $(50,00 \%)$ dalam kategori sedang, 7 orang $(23,33 \%)$ dalam kategori kurang, 1 orang $(3,33 \%)$ dalam kategori sedang, sehingga dapat di simpulkan prespsi Guru pendidikan jasmani sekolah Dasar negeri se kecamatan sewon dalam penaganan dini cedera olahraga dengan RICE( Rest Ice Compression dan Elevation)

Dipublikasikan Oleh : 
adalah sedang. Berdasarkan penelitian terdahulu, yang menjadi perbedaan dalam penelitian ini yaitu pertama, Sampel yang digunakan. Kedua, pembaharuan instrumen penelitian yang menyesuaikan pengetahuan guru pjok tentang metode RICE di SMA \& SMK se-Kecamatan Telukjambe Timur

Oleh sebab itu peneliti tertarik mengambil judul Survey Pengetahun Guru PJOK Tentang Penaganan Cedera Olahraga Dengan Menggunakan Metode Rest Ice Compression dan Elevation (RICE). Hal ini dapat membantu kelancaran proses pembelajaran dan mampu membantu siswa yang mengalami cedera dengan aman, sehingga perlu diadakan penelitian yang berguna untuk mengetahui pengetahuan guru pjok terhadap penanganan cedera olahraga dengan metode rest ice compression elevation (RICE) di SMP \& SMA seKecamatan Telukjambe Timur

\section{METODE}

Penelitian ini menggunakan metode deskriptif dengan pendekatan kuantitatif melalui penggunaan instrumen Angket untuk mengetahui pengetahuan guru pjok tentang penanganan cedera olahraga dengan metode RICE.

Sebelum kuisioner digunakan, maka diperlukan uji instrumen berupa uji validasi konstruksi (expert judgement) yang telah diujikan oleh Dosen Pengampu mata kuliah Penanganan Pertama Cedera Olahraga Evi Susianti, S.Pd., M.Pd lalu uji validitas untuk mengukur ketepatan disetiap butir soal, digunakan teknik produk momen sari karl pearson dengan taraf signifikansi 5\%. Butir soal dikatakan valid apabila rhitung > rtabel ,untuk nilai rtabel dengan responden 10 orang adalah sebesar 0,875 . Setelah dilakukan perhitungan dapat diketahui terdapat 3 butir soal yang tidak valid yaitu butir soal nomor 5,36, dan 38. Jadi peneliti hanya memakai 36 butir soal dari total 39 butir soal, Dan dilakukan uji reabilitas dengan menggunakan rumus alpha cronbach dengan taraf signifikansi 5\%, suatu instrumen dikatakan reliable jika r11> rtabel, hasil uji reabilitas diperoleh nilai r11 = 0,749> rtabel $=0,632$ dengan demikian menunjukan angket yang diuji cobakan reliable dan dapat digunakan untuk pengumpulan data penelitian.

Adapun Desain dalam penelitian yang dilakukan dalam penelitian ini menggunakan langkah langkah penelitian kuantitatif deskriptif terdiri dari: 1.) Mengidentifikasi adanya permasalahan yang signifikan untuk dipecahkan melalui metode deskriptif, 2.) Membatasi dan merumuskan permasalahan secara jelas, 3.) Menentukan tujuan dan manfaat penelitian, 4.) Melakukan studi pustaka yang berkaitan dengan permasalahan, 5.) Menentukan kerangka berpikir, dan pertanyaan penelitian dan atau hipotesis penelitian, 6.) Mendesain metode penelitian yang hendak digunakan termasuk dalam hal ini menentukan populasi, sampel, teknik sampling, menentukan instrumen, mengumpulkan data, dan menganalisis data, 7.) Mengumpulkan, mengorganisasikan, dan menganalisis data dengan menggunakan teknik statistika yang relevan, dan 8.) Membuat laporan penelitian.

Populasi dalam penelitian ini adalah guru pjok di SMA \& SMK di Kecamatan Telukjambe Timur dengan jumlah 16 guru pjok. penentuan jumlah sampel (Sugiyono, 2013). Sampel merupakan bagian berdasarkan jumlah dan karakteristik yang dimiliki oleh populasi tersebut (Sugiyono, 2010) magsud pengertian tersebut adalah bagian populasi yang hendak di teliti dan mewakili populasi dan apabila populasi berjumlah kurang dari 100 maka sempel yang di ambil adalah semuanya, tetapi apabila populasi penelitian berjumlah lebih dari 100 maka sempel yang di ambil 10\% - 15\% atau 20\% - 25\% atau lebih (Arikunto, 2014). Pada penelitian ini menggunakan teknik pengambilan sempel yaitu total sampling(Sugiyono, 2010). Dalam perhitungan statistik menggunakan bantuan aplikasi microsof texcel 2013. Selanjutnya data disajikan dalam bentuk tabel frekuensi dan kemudian dilakukan pengkategorian serta menyajikan data dalam bentuk histogram. Dalam pengkategorian skor mengunakan lima kategori yaitu, sangat baik, baik, cukup baik, kurang baik, dan sangat kurang baik(Sudijono, 2012:140).

Tabel 1. Norma Pengkategorian

\begin{tabular}{cc}
\hline Interval & Kategori \\
\hline $\mathrm{M}+1,5 \mathrm{SD} \leq \mathrm{X}$ & Sangat baik \\
$\mathrm{M}+0,5 \mathrm{SD} \leq \mathrm{X}<\mathrm{M}+1,5 \mathrm{SD}$ & Baik \\
$\mathrm{M}-0,5 \mathrm{SD} \leq \mathrm{X}<\mathrm{M}+0,5 \mathrm{SD}$ & Cukup baik \\
$\mathrm{M}-1,5 \mathrm{SD} \leq \mathrm{X}<\mathrm{M}-0,5 \mathrm{SD}$ & Kurang baik
\end{tabular}

Dipublikasikan Oleh :

UPT Publikasi dan Pengelolaan Jurnal

Universitas Islam Kalimantan Muhammad Arsyad Al-Banjari Banjarmasin 
Keterangan.

X : Skor yang diperoleh

SD : standar deviasi

M : mean (rata-rata)

Data disajikan dalam bentuk frekuensi relatif yang yang dituangkan dalam bentuk angka prosentase. Untuk memperoleh persentase digunakan rumus:

Keterangan:

\section{$\mathrm{p}=\mathbf{f} / \mathbf{N} \times 100 \%$}

$\begin{array}{ll}\mathrm{P} & \text { : angka persentase } \\ \mathrm{F} & \text { : frekuensi } \\ \mathrm{N} & \text { : jumlah subjek/ responden }\end{array}$

\section{HASIL DAN PEMBAHASAN}

Berdasarkan hasil penelitian yang telah diperoleh di lapangan mengenai menyesuaikan pengetahuan guru pjok tentang metode RICE di SMA \& SMK se-Kecamatan Telukjambe Timur Peneliti akan mendeskripsikan dan menganalisis data tersebut menggunakan metode deskriptif dengan pendekatan kuantitatif. Untuk memperoleh data dalam penelitian ini, peneliti menggunakan instrumen Angket (geogle Form) menggunakan kuisioner berupa soal pernyataan. Adapun dalam menyusun butir-butir pertanyaan, peneliti menetapkan faktor Metode RICE secara umum dengan indikator yaitu, menguraikan pengetahuan tentang rest (mengistirahatkan), ice (kompres dengan es), compression (balut tekan ), elevation (meninggikan).

Tabel 2. Skor Hasil Statistik Deskriptif Penelitian

\begin{tabular}{cccccc}
\hline Keterangan & Keseluruhan & $\begin{array}{c}\text { Rest } \\
\text { (mengisti } \\
\text { rahatkan) }\end{array}$ & $\begin{array}{c}\text { Ice } \\
\text { (mengompres } \\
\text { dengan es) }\end{array}$ & $\begin{array}{c}\text { Compression } \\
\text { (balut tekan) }\end{array}$ & $\begin{array}{c}\text { Elevation } \\
\text { (meningginkan) }\end{array}$ \\
\hline $\begin{array}{c}\text { Mean } \\
\text { Standar }\end{array}$ & 146,38 & 38,19 & 40 & 38,75 & 29,44 \\
Deviasi & 15,29 & 3,15 & 5,62 & 6,05 & 2,83 \\
Median & 138 & 38,5 & 38 & 37,5 & 29,5 \\
Range & 41 & 12 & 19 & 19 & 11 \\
Minimum & 128 & 33 & 30 & 28 & 24 \\
Maximum & 169 & 45 & 49 & 47 & 35 \\
\hline
\end{tabular}

Hasil analisis data statistik penelitian secara kesuluruhan memproleh nilai mean sebesar 146,38, standar deviasi 15,29, median sebesar 138, range sebesar 41, minimum sebesar 28, dan nilai maxsimal sebesar 169, maka data pengetahuan guru pjok tentang penanganan cedera olahraga dengan Metode Rest Ice Compression Elevation (RICE) di SMA \& SMK Sekecamatan TelukJambe Timur sebagai berikut:

Tabel 3. Skor Hasil Statistik Deskriptif Penelitian

\begin{tabular}{ccccc}
\hline No & Interval & Kategori & Frekuensi & $\%$ \\
\hline 1 & $\mathrm{X}>169.31$ & Sangat Baik & 0 & $0 \%$ \\
2 & $154.02<\mathrm{X}<169.31$ & Baik & 6 & $38 \%$ \\
3 & $138,73<\mathrm{X}<154,02$ & Cukup Baik & 2 & $13 \%$ \\
4 & $123.44<\mathrm{X}<138,73$ & Kurang Baik & 8 & $50 \%$ \\
5 & $\mathrm{X}<123.44$ & Sangat Tidak Baik & 0 & $0 \%$ \\
\hline
\end{tabular}

Dipublikasikan Oleh :

UPT Publikasi dan Pengelolaan Jurnal

Universitas Islam Kalimantan Muhammad Arsyad Al-Banjari Banjarmasin 
Berdasarkan tabel 3, hasil penelitian diketahui pengetahuan guru pjok tentang penanganan cedera olahraga dengan metode RICE di SMA \& SMK Sekecamatan TelukJambe Timur berada pada kategori "sangat baik" sebesar 0\% (0 guru), kategori "baik" sebesar 38\% (6 guru), kategori “cukup baik" sebesar 13\% (2 guru), kategori "kurang baik" sebesar 50\% (8 guru), dan Kategori "sangat tidak baik" sebesar 0\% (0 guru). Sedangkan berdasarkan nilai rata-rata yaitu 146,38 dari jumlah 36 butir soal. Jadi dapat di simpulkan bahwa secara keseluruhan pengetahuan guru PJOK tentang penanganan cedera olahraga dengan metode RICE di SMA \& SMK Sekecamatan TelukJambe Timur berada di kategori kurang baik. Apabila digambarkan dalam diagram batang sebagai berikut:

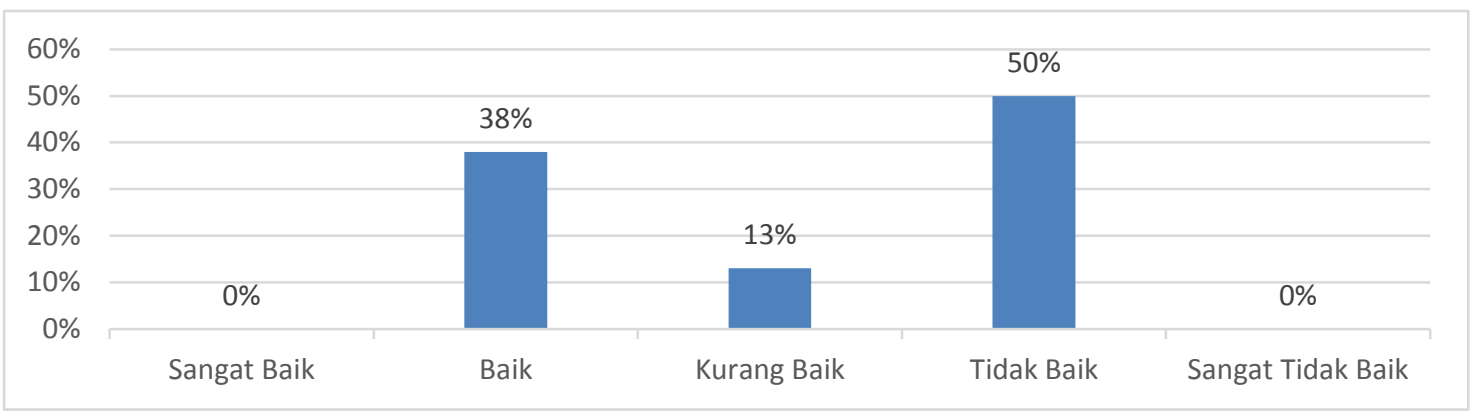

Gambar 1. Diagram Batang Pengetahuan Guru Pjok Keseluruhan

\section{Pengetahuan Tentang Rest (Mengistirahatkan)}

Berdasarkan hasil penelitian dari indikator pengetahuan tentang Rest (mengistirahatkan) diproleh mean sebesar 38,19, satandar deviasi 3,15, range 12, skor minimal 33, dan skor maksimal 45. Setelah diketahui dapat dimasukan kedalam tebel distribusi frekuesi sebagai berikut:

Tabel 4. Skor Distribusi Frekuensi Pengetahuan Rest (mengistirahatkan)

\begin{tabular}{ccccc}
\hline No & Interval & Kategori & Frekuensi & $\%$ \\
\hline 1 & $\mathrm{X}>42,91$ & Sangat Baik & 1 & $6 \%$ \\
2 & $39,76<\mathrm{X}<42,91$ & Baik & 3 & $19 \%$ \\
3 & $36,61<\mathrm{X}<39,76$ & Cukup Baik & 6 & $38 \%$ \\
4 & $33,47<\mathrm{X}<36,61$ & Kurang Baik & 5 & $31 \%$ \\
5 & $\mathrm{X}<33,47$ & Sangat Tidak Baik & 1 & $6 \%$ \\
\hline
\end{tabular}

Berdasarkan tabel 4, di atas dapat dijelaskan bahwa secara indikator pengetahuan guru PJOK tentang penanganan cedera olahraga metode RICE di SMA \& SMK Sekecamatan TelukJambe Timur, secara rinci terdapat 1 guru (6\%) kategori sangat baik, 3 guru (19\%) kategori baik, 6 guru (38\%) cukup baik, 5 guru (31\%) kurang baik, 1 guru (6\%) sangat tidak baik. Frekuensi terbanyak pada kategori sejumlah 6 guru cukup baik (38\%), sehingga dapat disimpulkan indikator pengetahuan guru PJOK tentang penanganan cedera olahraga metode RICE di SMA \& SMK Sekecamatan TelukJambe Timur termasuk dalam kategori kurang baik. Apabila digambarkan dalam bentuk diagram batang diproleh sebagai berikut:

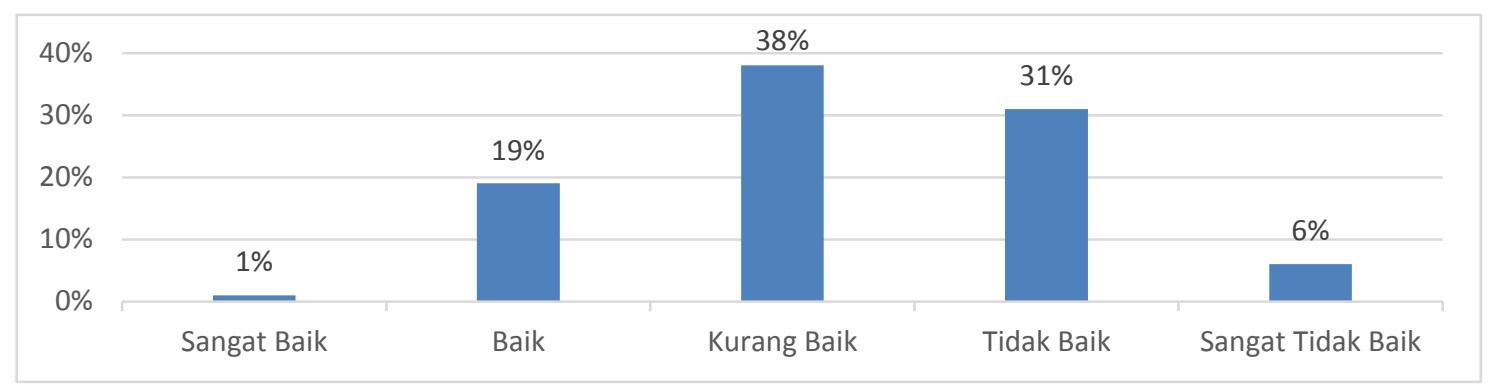

Gambar 2. Diagram Batang Pengetahuan Rest (mengistirahatkan)

Dipublikasikan Oleh :

UPT Publikasi dan Pengelolaan Jurnal

Universitas Islam Kalimantan Muhammad Arsyad Al-Banjari Banjarmasin 


\section{Pengetahuan Tentang Ice (Kompres Es)}

Berdasarkan hasil penelitian dari indikator pengetahuan tentang Ice (kompres es) diproleh mean sebesar 40, satandar deviasi 5,26, range 19, skor minimal 30, dan skor maksimal 49. Setelah diketahui dapat dimasukan kedalam tebel distribusi frekuesi sebagai berikut:

Tabel 5. Skor Distribusi Frekuensi Pengetahuan Ice (Kompres Es)

\begin{tabular}{ccccc}
\hline No & Interval & Kategori & Frekuensi & $\%$ \\
\hline $\mathbf{1}$ & $\mathrm{X}>48,43$ & Sangat Baik & 1 & $6 \%$ \\
$\mathbf{2}$ & $42,81<\mathrm{X}<48,43$ & Baik & 5 & $19 \%$ \\
$\mathbf{3}$ & $37,19<\mathrm{X}<42,81$ & Cukup Baik & 3 & $38 \%$ \\
$\mathbf{4}$ & $31,57<\mathrm{X}<37,19$ & Kurang Baik & 5 & $31 \%$ \\
$\mathbf{5}$ & $\mathrm{X}<31,57$ & Sangat Tidak Baik & 1 & $6 \%$ \\
\hline
\end{tabular}

Berdasarkan tabel 4.4 di atas dapat dijelaskan baw pengetahuan guru PJOK tentang penanganan cedera olahraga metode RICE di SMA \& SMK Sekecamatan TelukJambe Timur, secara rinci terdapat 1 guru (6\%) kategori sangat baik, 5 guru (31\%) kategori baik, 3 guru (19\%) cukup baik, 6 guru (38\%) kurang baik, 1 guru (6\%) sangat tidak baik. Frekuensi terbanyak pada kategori sejumlah 6 guru tidak baik (38\%), sehingga dapat disimpulkan indikator pengetahuan guru PJOK tentang penanganan cedera olahraga metode RICE di SMA \& SMK Sekecamatan TelukJambe Timur termasuk dalam kategori cukup baik. Apabila digambarkan dalam diagram batang sebagai berikut:

Grafik 3. Diagram Batang Pengetahuan Ice (Komres Es)

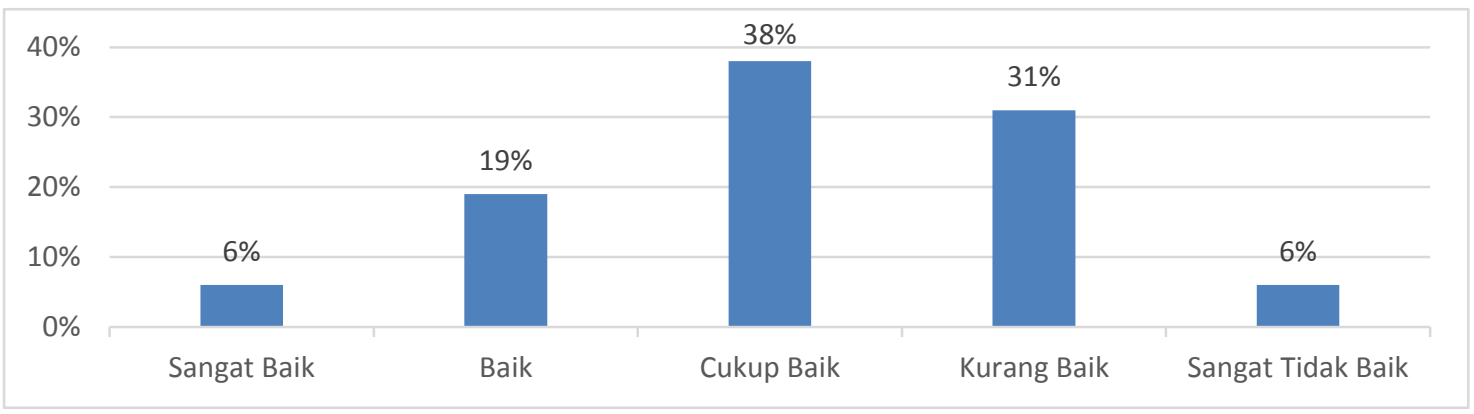

Pengetahuan Tentang Compression (Balut Tekan)

Pengetahuan tentang compression (balut tekan) diproleh mean sebesar 38,75, satandar deviasi 6,05, range 19 , skor minimal 28, dan skor maksimal 47. Setelah diketahui dapat dimasukan kedalam tebel distribusi frekuesi sebagai berikut :

Tabel .6 Skor Distribusi Frekuensi Pengetahuan Compression (Balut Tekan)

\begin{tabular}{ccccc}
\hline No & Interval & Kategori & Frekuensi & $\%$ \\
\hline $\mathbf{1}$ & $\mathrm{X}>47,82$ & Sangat Baik & 0 & $0 \%$ \\
$\mathbf{2}$ & $41,77<\mathrm{X}<47,82$ & Baik & 7 & $44 \%$ \\
$\mathbf{3}$ & $35,73<\mathrm{X}<41.77$ & Cukup Baik & 3 & $19 \%$ \\
$\mathbf{4}$ & $29,68<\mathrm{X}<35,73$ & Kurang Baik & 5 & $31 \%$ \\
$\mathbf{5}$ & $\mathrm{X}<29,68$ & Sangat Tidak Baik & 1 & $6 \%$ \\
\hline
\end{tabular}

Berdasarkan tabel 6, diatas dapat dijelaskan baw pengetahuan guru PJOK tentang penanganan cedera olahraga metode RICE di SMA \& SMK Sekecamatan Telukjambe Timur, secara rinci terdapat o guru (0\%) kategori sangat baik, 7 guru (44\%) kategori baik, 3 guru (19\%) cukup baik, 5 guru (31\%) kurang baik, 1 guru (6\%) sangat tidak baik. Frekuensi terbanyak pada kategori sejumlah 7 guru tidak baik $(44 \%)$, sehingga dapat disimpulkan indikator pengetahuan guru PJOK tentang penanganan cedera olahraga metode RICE di SMA \& SMK Sekecamatan TelukJambe Timur termasuk dalam kategori baik. Apabli digambarkan dengan diagram batang sebagai berikut :

Dipublikasikan Oleh :

UPT Publikasi dan Pengelolaan Jurnal

Universitas Islam Kalimantan Muhammad Arsyad Al-Banjari Banjarmasin 


\section{Gambar 4. Diagram Batang Pengetahuan Compression (Balut Tekan)}

\section{Pengetahuan Tentang Elevation (Meninggikan)}

Berdasarkan hasil penelitian dari indikator pengetahuan tentang Elevation (meninggikan) diproleh mean sebesar 29,44, satandar deviasi 2,83, range 11, skor minimal 24, dan skor maksimal 35. Setelah diketahui dapat

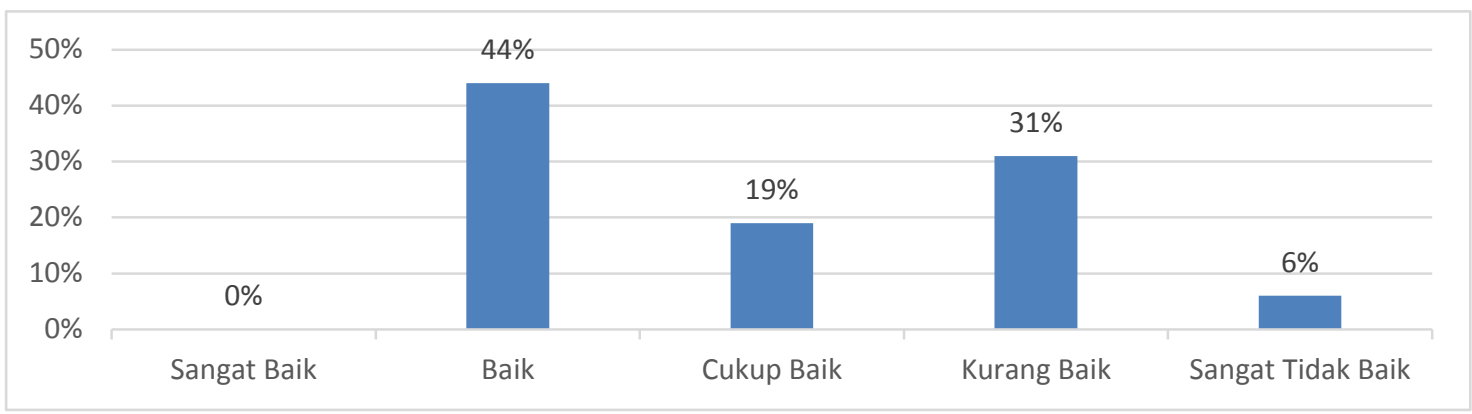

dimasukan kedalam tabel distribusi frekuensi sebagai berikut :

Tabel 7. Skor Distribusi Frekuensi Pengetahuan Elevation (Meninggikan)

\begin{tabular}{ccccc}
\hline No & Interval & Kategori & Frekuensi & $\%$ \\
\hline $\mathbf{1}$ & $\mathrm{X}>33,68$ & Sangat Baik & 1 & $6 \%$ \\
$\mathbf{2}$ & $30,85<\mathrm{X}<33,68$ & Baik & 5 & $31 \%$ \\
$\mathbf{3}$ & $28,02<\mathrm{X}<30.85$ & Cukup Baik & 4 & $25 \%$ \\
$\mathbf{4}$ & $25,20<\mathrm{X}<28,02$ & Kurang Baik & 4 & $25 \%$ \\
$\mathbf{5}$ & $\mathrm{X}<25,02$ & Sangat Tidak Baik & 2 & $13 \%$ \\
\hline
\end{tabular}

Berdasarkan tabel 7, dapat dijelaskan baw pengetahuan guru PJOK tentang penanganan cedera olahraga metode RICE di SMA \& SMK Sekecamatan TelukJambe Timur, secara rinci terdapat 1 guru (6\%) kategori sangat baik, 5 guru (31\%) kategori baik, 4 guru (25\%) cukup baik, 4 guru (25\%) tidak baik, 2 guru (13\%) sangat tidak baik. Frekuensi terbanyak pada kategori sejumlah 5 guru baik (31\%), sehingga dapat disimpulkan faktor pengetahuan guru PJOK tentang penanganan cedera olahraga metode RICE di SMA \& SMK Sekecamatan TelukJambe Timur termasuk dalam kategori baik. Apabila digambarkan dalam diagram batang sebagai berikut :

Gambar 5. Diagram Batang Pengetahuan Elevation (Meninggikan)

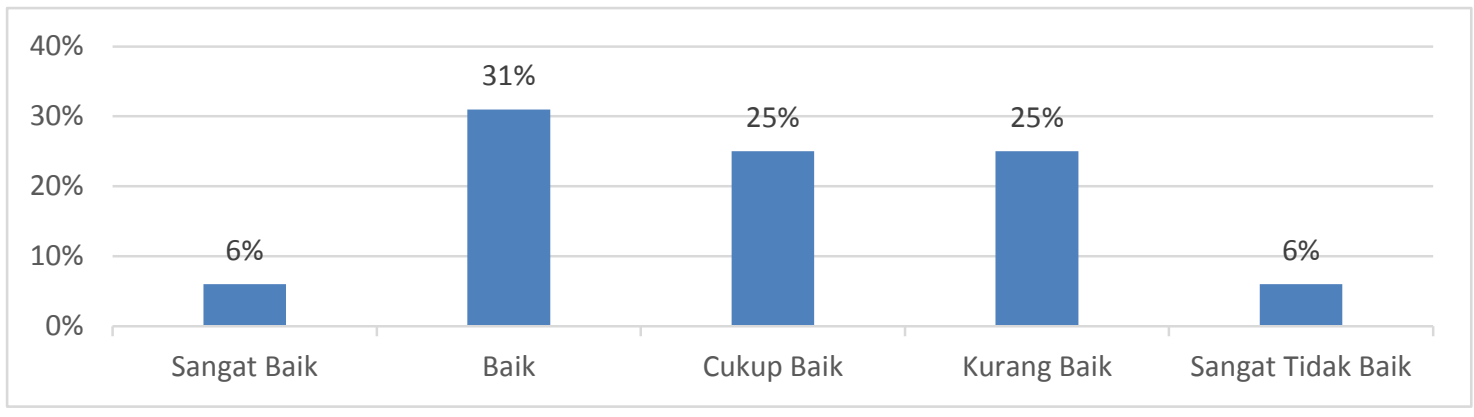

PENUTUP

Berdasarkan hasil penelitian diketahui pengetahuan guru PJOK tentang penanganan cedera olahraga dengan metode RICE di SMA \& SMK Sekecamatan TelukJambe Timur berada pada kategori "sangat baik" sebesar 0\% (0 guru), kategori "baik" sebesar 38\% (6 guru), kategori "cukup baik" sebesar 13\% (2 guru), kategori "kurang baik" sebesar 50\% (8 guru), dan Kategori "sangat tidak baik" sebesar 0\% (0 guru). Sedangkan berdasarkan nilai

Dipublikasikan Oleh :

UPT Publikasi dan Pengelolaan Jurnal

Universitas Islam Kalimantan Muhammad Arsyad Al-Banjari Banjarmasin 
rata-rata yaitu 146,38 dari jumlah 36 butir soal. Jadi dapat di simpulkan bahwa secara keseluruhan pengetahuan guru pjok tentang penanganan cedera olahraga dengan metode RICE di SMA \& SMK Sekecamatan TelukJambe Timur berada di kategori kurang baik. Karena hasil yang ditunjukan data kurang baik perlu adanya pelatihan khusus guru pjok tentang pengetahuan cedera olahraga di Kecamatan Telukjambe Timur agar pembelajaran olahraga tercapai dan membantu siswa siswi meraih prestasi sesuai dengan keahliannya dibidang olahraga

\section{REFERENSI}

Arikunto, S. (2014). Prosedur Penelitian (cetakan kelima belas). Jakarta: PT. Rineka Cipta.

Arsani, N. L. K. A. (2019). Tingkat pengetahuan para praktisi olahraga di Kabupaten Buleleng dalam memberikan pertolongan pertama terhadap cedera olahraga dengan metode RICE. Medicina, 50(3), 600. https://doi.org/10.15562/Medicina.v50i3.872

Fauzi, R., Achmad, I. Z., \& R, A. K. Y. (2020). Tingkat Pemahaman Siswa Kelas X Dalam Pembelajaran Daring Pendidikan Jasmani Di Sman 2 Cikarang Pusat. Jurnal Pendidikan Olahraga, 3(2), 37-46.

Jamaliah, N. (2019). Peningkatan Hasil Belajar Passing Bawah Bola Voli Melalui Torgamba Kabupaten Labuhan Batu Selatan Model Pbbt Dan Pbkl Siswa Kelas Viii Smpn 1. Universitas Islam Kalimantan Muhammad Arsyad Al-Banjari Banjarmasin, 1-8.

Normaisyah, H., Perdana, A. D. I., Junaidi, D. H. S., Pd, M., Harmono, H. S., Pd, M., Ilmu, F., Dan, K., Fiks, S., Normaisyah, H., \& Perdana, A. D. I. (2020). RICE PADA GURU PJOK TINGKAT MADRASAH IBTIDAIYAH SE-KECAMATAN MOJO KABUPATEN KEDIRI TAHUN 2019 Oleh: Dibimbing oleh: UNIVERSITAS NUSANTARA PGRI KEDIRI SURAT PERNYATAAN ARTIKEL SKRIPSI TAHUN 2020.

Sihaloho, A. S. (2019). SURVEY PENANGANAN CEDERA DI SEKOLAH OLEH GURU PENJASKES DI TINGKAT SMA / SMK NEGERI DI KECAMATAN PATI TAHUN 2016 SKRIPSI.

Sudijono, A. (2012). Pengantar Statistik. Raja Grafindo Persada, Jakarta.

Sugiyono, D. (2010). Metode penelitian kuantitatif kualitatif dan R\&D. xiii.

Sugiyono, P. D. (2013). Statistik untuk Penelitian. CV. Alvabeta Bandung.

Tommy Fondy,M.Pd. (2016). Sport Massage : Panduan Praktis Merawat dan Mereposisi Cedera.

Wijaya, I. M. K., Wahyuni, P. D. S., Setiawan, K. H., \& Giri, M. K. W. (2019). Pelatihan Pertolongan Pertama Pada Cedera Olahraga Bagi Siswa Dan Guru Sekolah Dasar Kecamatan Negara. Seminar Nasional Pengabdian Kepada Masyarakat, 4, 488-495.

Dipublikasikan Oleh :

UPT Publikasi dan Pengelolaan Jurnal

Universitas Islam Kalimantan Muhammad Arsyad Al-Banjari Banjarmasin 